Lijun Wang*, Jianhui Qiu and Eiichi Sakai

\title{
Mechanical and electrical properties of polylactic acid/carbon nanotube composites by rolling process
}

DOI 10.1515/secm-2017-0113

Received April 3, 2017; accepted June 18, 2017; previously published online July 21, 2017

Abstract: In this work, the rolling process was employed to fabricate polylactic acid/multi-walled carbon nanotube (PLA/MWCNT) composites at room temperature. The effects of the rolling conditions on the mechanical and electrical properties of the fabricated composites were investigated. The evolution processes of the internal molecular structures, i.e. changes in molecular orientation and crystallinity, were examined by X-ray diffraction, differential scanning calorimetry, and density method. The results suggested that the molecular orientation improved; however, the crystallinity decreased when the rolling ratio increased. The analysis of the mechanical properties revealed that the rolled composites displayed anisotropy during the rolling process. In the rolling direction, after adding 1 wt.\% MWCNTs, the tensile strength increased from 58.6 to $94.3 \mathrm{MPa}$ with the rolling ratio, whereas the fracture strain sharply increased to $131.5 \%$ at the rolling ratio of $60 \%$. In addition to the mechanical properties, electrical resistivity was also investigated; notably, this property was not significantly affected by the rolling process. Furthermore, the MWCNT dispersion and morphology were investigated by scanning electron microscopy. These findings offer a simple and effective method to fabricate conductive composites with excellent mechanical properties.

Keywords: carbon nanotubes; electrical properties; mechanical properties; polylactic acid; rolling process.

*Corresponding author: Lijun Wang, Department of Mechanical and Biofunctional Systems, Institute of Industrial Science, The University of Tokyo, 4-6-1 Komaba, Meguro-ku, Tokyo 153-8505, Japan, e-mail: wanglijun1031@163.com Jianhui Qiu and Eiichi Sakai: Department of Machine Intelligence and Systems Engineering, Faculty of System Science and Technology, Akita Prefectural University, 84-4 Tsuchiya Ebinokuchi, Yurihonjo, Akita 015-0055, Japan

\section{Introduction}

In modern society, the demand for polymers is becoming increasingly strong. In our daily life, many products, such as auto parts, electronic devices, and even structural elements in the field of aerospace, cannot be fabricated without polymers [1, 2]. However, owing to their lack of conductivity (except for conducting polymers), polymers are hardly employed when electrical resistivity needs to assume different values for different applications. For electromagnetic shielding, electrical resistivity is required to be from $\sim 10^{11}-10^{12} \Omega / \mathrm{sq}$, whereas for electrostatic coating, only small electrical resistivity of $\sim 10^{7}-10^{8} \Omega / \mathrm{sq}$ is necessary [3]. Therefore, the control of the electrical resistivity in polymers has become a main challenge for the development of conductive polymer composites (CPCs).

Muller et al. [4] and Villmow's group [5] demonstrated that the addition of conductive particles to polymers simply makes them conductive. A wide variety of conductive particles are available, such as metal particles, carbon fibers, carbon nanotubes (CNTs), grapheme, etc. Nowadays, the most mature technology involves the use of CNTs to prepare polymer/CNT composites, due to their excellent electrical and mechanical properties. Moreover, given that the technology for preparing CNTs has been already developed, and the production cost is relatively low, CNTs have recently been investigated by many researchers. However, the only drawback is that CNTs very easily agglomerate in polymers, which not only affects their native conductive properties, but also reduces their mechanical properties. Therefore, CNT agglomeration is a burning issue that affects the mechanical and electrical properties of the composites.

Meanwhile, as polymer applications are expanding, environmental pollution and recycling have become crucial. Lack of degradability and the closing of landfill sites as well as growing water and land pollution problems have emerged in an endless stream. In this context, growing awareness of the waste problem and its impact on the environment has awakened new interest in the area of degradable polymers [6]. Biodegradable polymers, such as polylactic acid (PLA), polybutylene succinate, 
polycaprolactone, and polyhydroxyalkanoates, have recently attracted increasing interest as alternative matrices. PLA, a promising biodegradable and thermoplastic polymer, can be derived from renewable resources such as starch and is a sustainable alternative to petrochemicalderived products [7]. Moreover, it is a well-studied environmentally friendly polymer with good strength [8] and high stiffness [9], and is used in many applications, such as packaging materials [7], degradable plastic bags, water and milk bottles, as well as in the automotive field $[10,11]$. Accordingly, the increasing use of PLA as an environmentally friendly polymer could replace traditional polymers in potential industrial applications.

Therefore, in the current work, PLA was used as the matrix polymer. Additionally, as reported by Ata's group [12], the matching between the solubility parameters of CNTs and polymer matrix is advantageous in achieving high electrical conductivity in polymer/CNT composites; thus, in our work, multi-walled CNTs (MWCNTs) were selected and used as the reinforced fillers. Moreover, as suggested in our previous studies [13], the rolling process is an excellent method to enhance the mechanical properties of polymers. Hence, it as adopted in the current work to fabricate PLA/MWCNT composites. In this study, the effects of the rolling conditions on the mechanical and electrical properties of the prepared composites were investigated, and the MWCNT morphologies (dispersion and distribution) were observed by scanning electron microscopy (SEM). Like most other aliphatic polyesters, PLA presents a slower crystallinity ratio and exhibits variations in crystal structure and crystallinity after being subjected to different molding processes [14-16]. Moreover, its orientation strongly affects the mechanical properties, as reported by Nadella and $\mathrm{Yu}[17,18]$. Therefore, the variation of crystallinity at different rolling ratios was investigated by both differential scanning calorimetry (DSC) and density method; the orientation was also studied by X-ray diffraction (XRD). The experimental results confirmed that the mechanical and electrical properties of PLA composites were reinforced by the rolling process. These results provide a convenient method through which to fabricate PLA/MWCNT composites as environmentally friendly CPCs.

\section{Materials and methods}

\subsection{Materials}

Here, PLA (Ingeo 3001D type supplied by Nature Works LLC, USA) with residual moisture content $<0.025 \%$ was used to prevent viscosity degradation. The melt flow index was $22 \mathrm{~g} /(10 \mathrm{~min})$, and the density was $1.24 \mathrm{~g} / \mathrm{cm}^{3}$, according to ASTM D1238 and ASTM D792, respectively. MWCNTs were purchased from Shouwa Denko Company (VGCF-X type, Tokyo, Japan); the diameter ranged from $10-15 \mathrm{~nm}$, and the average length was $\sim 3 \mu \mathrm{m}$. They were used without any purification process.

\subsection{Specimen preparation and rolling process}

The compounding processes of the PLA/MWCNT master batches were conducted using a twin-screw extruder (KZX25TW-60MG-NH (-1200)-AKT, Technovel Co., Ltd, Japan). The conditions used for the compounding processes were the same as those employed in our previous research [19]. The original materials (i.e. PLA and MWCNTs) were vacuum-dried at $50^{\circ} \mathrm{C}$ for $8 \mathrm{~h}$ prior to the process; PLA was then compounded with $0,1,3,5$, and 10 wt.\% MWCNTs, followed by the pelletizing step. All master batches were cooled down in a water bath.

Prior to the extrusion process, the pelletized master batches were again dried at $50^{\circ} \mathrm{C}$ for $8 \mathrm{~h}$, and the composite sheets were prepared by the same extruder. The temperature of $150^{\circ} \mathrm{C}-190^{\circ} \mathrm{C}$ was used to prepare PLA/ MWCNT sheets with $0,1,3$, and 5 wt.\% MWCNTs. Meanwhile, to ensure excellent fluidity in the extruder, the temperature was set at $150^{\circ} \mathrm{C}-210^{\circ} \mathrm{C}$ to prepare PLA/MWCNT sheets with high MWCNT mass fraction (i.e. 10 wt.\%). Moreover, the stir rotation speed was $144 \mathrm{rpm}$; the extrusion speed for preparing sheets with low MWCNT mass fraction was $1.54 \mathrm{~mm} / \mathrm{s}$, whereas the extrusion speed for the $10 \mathrm{wt} . \%$ MWCNT composite sheets was $1.33 \mathrm{~mm} / \mathrm{s}$. Five different sheets were prepared under different processing conditions.

Subsequently, the rolling process was performed on the extruded sheets by a rolling machine (TKE-0; Imoto Machinery Co., Ltd., Kyoto, Japan) at room temperature. This step is similar as the method described previously [13]. The diameter and effective width of each roller were 100 and $150 \mathrm{~mm}$, respectively. The processes were performed under the conditions reported in Table 1 to evaluate the effects of the rolling ratio on the mechanical and electrical properties of the PLA/MWCNT composites. Owing to the difference in ductility for composites with different MWCNT mass fractions, the maximum rolling ratios also varied. As shown in our previous work [13], $2000 \times 100 \mathrm{~mm}^{2}$ (length $\times$ width) extruded sheets were machined into specimens with dimensions of $100 \times 80 \mathrm{~mm}^{2}$ to execute the rolling process. The thicknesses of the 
Table 1: Rolling process conditions for the fabricated composite sheets.

\begin{tabular}{rrrrrr}
\hline No. $\begin{array}{r}\text { MWCNT mass } \\
\text { fraction (wt.\%) }\end{array}$ & $\begin{array}{r}\text { Rolling } \\
\text { temperature }\left({ }^{\circ} \mathrm{C}\right)\end{array}$ & $\begin{array}{r}\text { Rolling speed } \\
(\mathbf{m} / \mathbf{m i n})\end{array}$ & $\begin{array}{r}\text { Ambient } \\
\text { humidity (\%) }\end{array}$ \\
\hline 1 & $23 \pm 2$ & 3 & $0,20,40,60,75$ & $30 \pm 2$ \\
2 & 0 & $23 \pm 2$ & 3 & $0,20,40,60,75$ & $30 \pm 2$ \\
3 & 1 & $23 \pm 2$ & 3 & $0,20,40,60,80$ & $30 \pm 2$ \\
4 & 3 & $23 \pm 2$ & 3 & $0,20,40,60,77$ & $30 \pm 2$ \\
5 & 5 & $23 \pm 2$ & 3 & $0,20,40,60,80$ & $30 \pm 2$ \\
\hline
\end{tabular}

sheets were in the range of $\sim 1.2-1.6 \mathrm{~mm}$, depending on the different MWCNT mass fractions. The rolling process was conducted at the rotation speed of $3 \mathrm{~m} / \mathrm{min}$ at room temperature $\left(23^{\circ} \mathrm{C} \pm 2^{\circ} \mathrm{C}\right)$, and the rolling direction was matched to the extrusion direction. The rolling ratio $\xi$ can be calculated by the following equation:

$$
\xi=\left[\left(\mathrm{H}_{0}-\mathrm{H}_{1}\right) / \mathrm{H}_{0}\right] \times 100 \%,
$$

where $\mathrm{H}_{0}$ and $\mathrm{H}_{1}$ are the thicknesses of the initial and rolled specimens, respectively.

Finally, the rolled sheets were cut along two different directions into dumbbell-shaped specimens (JST K7113) of $75 \times 10 \mathrm{~mm}^{2}$ in size and different thicknesses; one parallel (i.e. $0^{\circ}$ ) and one perpendicular (i.e. $90^{\circ}$ ) to the rolling direction, as shown in Figure 1. These specimens were used for evaluating the mechanical and electrical properties.

\subsection{Determination of molecular orientation}

The molecular orientation of the rolled PLA composites was determined by X-ray diffraction (XRD). The XRD patterns were recorded by using a Panalytical X’Pert Pro X-ray diffractometer (Cambridge, UK) with nickel filter $\mathrm{Cu} \mathrm{K}_{\alpha}$ radiation $(\lambda=0.15418 \mathrm{~nm}$; XRD-6000, Shimadzu Co., Ltd., Kyoto, Japan), and operated at the generator voltage of $45 \mathrm{kV}$ and tube current of $40 \mathrm{~mA}$. The $2 \theta$ scattering angle was in the range of $5^{\circ}-50^{\circ}$, whereas the scan speed was $2.13^{\circ} \mathrm{min}^{-1}$. The measurements were conducted in the

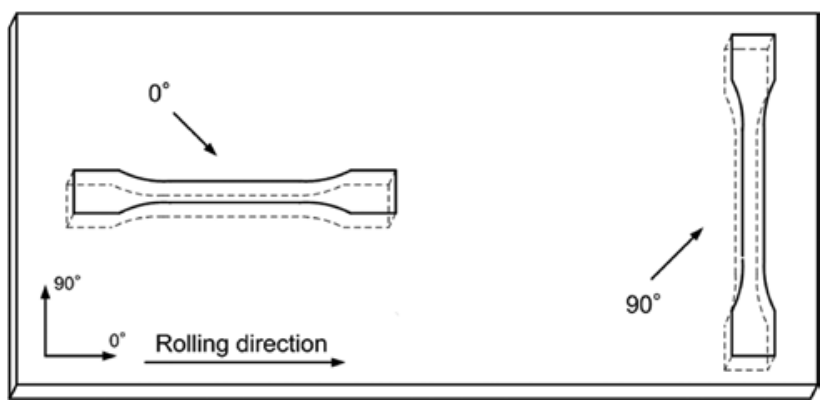

Figure 1: Angle between the specimens and the rolling direction. middle of three dumbbell-shaped specimens. Then, the molecular orientation is determined using the following equation, as reported by Kakudo and Kasai [20]:

$$
\mathrm{H}[\%]=100 \times(180-\mathrm{W}) / 180,
$$

where $\mathrm{W}$ is the half-width of the diffraction peak.

More than three specimens were measured, and the final molecular orientation was determined by the average value.

\subsection{Investigation of crystallization behaviors}

DSC was performed by using a DSC instrument (X-DSC7000, SII Nano Technology Inc., Japan). The granulated specimens (approximately $10 \mathrm{mg}$ ) for testing were cut from rolled sheets, and then scanned from $30^{\circ} \mathrm{C}$ to $200^{\circ} \mathrm{C}$ at the scan rate of $10^{\circ} \mathrm{C} / \mathrm{min}$ in a nitrogen atmosphere of $50 \mathrm{ml} / \mathrm{min}$. The heating process was conducted to investigate the influence of the rolling ratio on the crystallization behavior of the composites. Three specimens were then measured to ensure accuracy and credibility. The degree of crystallization $\chi_{c}$ of PLA and its composites is determined from the DSC heating traces by using the following equation, as reported by Tham et al. [21]:

$$
\chi_{c}=\left[\left(\Delta \mathrm{H}_{\mathrm{m}}-\Delta \mathrm{H}_{\mathrm{c}}\right) / \Delta \mathrm{H}_{\mathrm{m}}{ }^{0} \cdot(1-\mathrm{w})\right] \times 100 \%,
$$

where $\Delta \mathrm{H}_{\mathrm{m}}$ is the melting enthalpy during the heating process, $\Delta \mathrm{H}_{\mathrm{c}}$ is the enthalpy of crystallization, $\Delta \mathrm{H}_{\mathrm{m}}{ }^{0}$ is the enthalpy for $100 \%$ crystallization PLA ( $~ 93.6 \mathrm{~J} / \mathrm{g}$ as measured by Kalb and Pennings [22] and Tjong et al. [23]), and $\mathrm{w}$ is the MWCNT weight fraction.

The density of the composites was determined by employing the water displacement method (JIS K7112, method A), using an electronic gravity meter (SD-200L, Alfa Mirage Co., Ltd., Osaka, Japan). The measurements were performed on three dumbbell-shaped specimens at room temperature $\left(23^{\circ} \mathrm{C} \pm 2^{\circ} \mathrm{C}\right)$, and purified water was used. The density of the composites is calculated by using the following equation: 


$$
\rho=\left(m_{S, A} \times \rho_{I L}\right) /\left(m_{S, A}-m_{S, L}\right),
$$

where $m_{S, A}$ and $m_{S, L L}$ are the masses (g) of PLA in air and water, respectively, and $\rho_{I L}$ is the density of PLA in water $\left(\mathrm{g} / \mathrm{cm}^{3}\right)$.

Moreover, $\chi_{c}$ of PLA is determined by the density, using the following equation:

$$
\chi_{c}=\left[\left(\rho_{\mathrm{PLA}}-\rho_{a}\right) /\left(\rho_{c}-\rho_{a}\right)\right] \times 100 \%
$$

where $\rho_{\text {PLA }}$ is the actual density of PLA $(\mathrm{g} / \mathrm{ml}), \rho_{a}$ is the density of amorphous PLA $(1.248 \mathrm{~g} / \mathrm{ml})$, and $\rho_{c}$ is the density of $100 \%$ crystalline PLA $(1.290 \mathrm{~g} / \mathrm{ml})$, according to the reports by Nampoothiri et al. [24] and Wei and Ma [25].

Next, PLA actual density $\rho_{P L A}$ is calculated by using the following equation:

$$
\rho_{\text {PLA }}=m_{A}(1-w) /\left[v-\left(m_{A} \times w\right) / \rho_{\text {CNT }}\right],
$$

where $m_{A}$ is the mass of PLA in air (g), $w$ is the MWCNT mass fraction (wt.\%), $v$ is the volume of the measured specimen $\left(\mathrm{cm}^{3}\right)$, and $\rho_{\mathrm{CNT}}$ is the actual MWCNT density $\left(\mathrm{g} / \mathrm{cm}^{3}\right)$.

The MWCNT actual density was also measured by using the density method. Given that PLA is a crystalline polymer, the actual MWCNT density could not be obtained by measuring the PLA/MWCNT composite specimen. Thus, the density of a polycarbonate (PC)/MWCNT composite prepared in our previous work was measured, and the actual density of MWCNT was equal to $1.8574 \mathrm{~g} / \mathrm{cm}^{3}$.

\subsection{Tensile property tests}

The tensile properties, i.e. strength and fracture strain, of the cold-rolled PLA/MWCNT composites were measured by using a universal testing machine (3360, INSTRON Co., Ltd, Kanagawa, Japan). The measurements were conducted on dumbbell-shaped specimens at the tensile rate of $10 \mathrm{~mm} / \mathrm{min}$ and room temperature $\left(23^{\circ} \mathrm{C} \pm 2^{\circ} \mathrm{C}\right)$. Then, the values obtained for five specimens were averaged to determine the tensile properties of each group.

\subsection{Electrical property tests}

Electrical resistivity was measured on dumbbell-shaped specimens. In the measurements, different instruments were employed for the different ranges of electrical resistivity; in the range of $0-10^{4} \Omega / \mathrm{sq}$, a four-probe resistivity tester (SDY-4, Guangzhou Semiconductor Material Academy Co., Ltd.) was employed, whereas for values higher than $10^{4} \Omega / \mathrm{sq}$, a double-loop resistance meter (UPMCP-HT450, Mitsubishi Chemical Co., Ltd., Tokyo, Japan) was used. The measurement of each specimen was repeated more than five times, and the average value was chosen as the electrical resistivity of the specimen.

\subsection{Microscopy analysis}

The microstructures of the tensile fracture surfaces of the composites were observed by SEM (Hitachi Ltd S-4300, Tokyo, Japan) to investigate the dispersion and distribution of MWCNTs in PLA. Prior to the SEM observation, the specimens were sputter-coated with $\mathrm{Au}$, using an ion sputtering apparatus (E-1030, Hitachi Science Systems Co., Ltd., Tokyo, Japan) to avoid charging. The acceleration voltage was set to $3 \mathrm{kV}$.

\section{Results and discussion}

\subsection{Effects of rolling ratio on orientation}

In a previous work, we found that the rolling process greatly affects the molecular orientation and crystallization of crystalline polymers [13]; similar forms of evidence were proposed by Marubayashi et al. [26] and Murata et al. [27]. Therefore, in the current work, the orientation behaviors of the rolled composites were examined by using XRD. Figure 2 shows the XRD patterns in the $2 \theta$ range of $5^{\circ}-50^{\circ}$ for PLA/MWCNT composites with different MWCNT mass
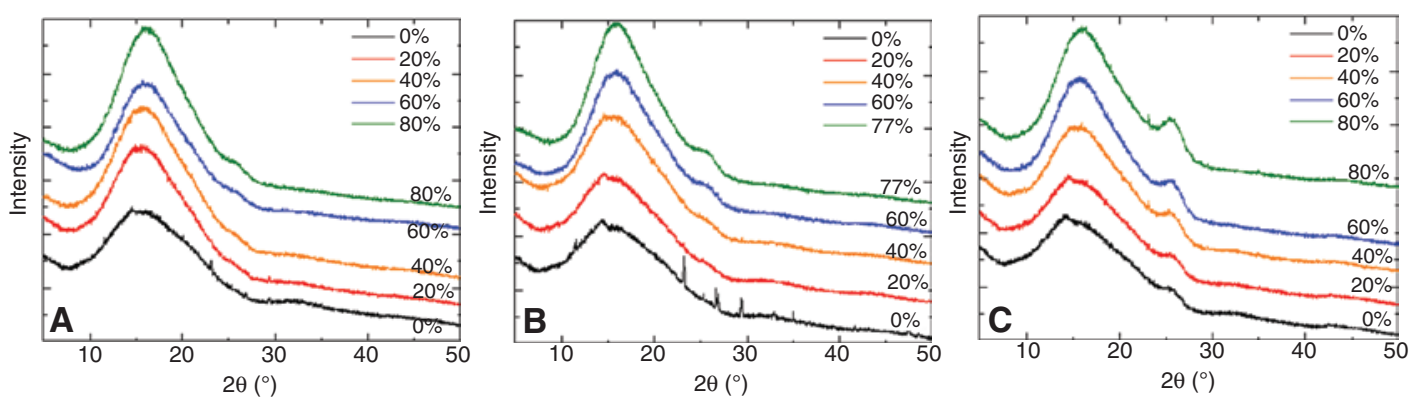

Figure 2: X-ray diffraction curves of composites with (A) 3wt.\%, (B) 5wt.\%, and (C) 10wt.\% MWCNTs at various rolling ratios. 
fractions (i.e. 3, 5, and 10 wt.\%). For the unrolled composite specimens, i.e. $0 \%$ rolling ratio, a high intensity peak was observed at $2 \theta=16.7^{\circ}$, which coincided with the diffraction peak of pure PLA, as previously reported by our group [13]. Marubayashi et al. [26] reported that this was due to reflections from the (110) and (200) planes, and belonged to the $\alpha$-crystal form of PLA. As shown in Figure 2, no distinct effect of the rolling ratios on the diffraction peak position could be observed. However, there were significant differences in intensity, namely, the intensity of the diffraction peak at $2 \theta=16.7^{\circ}$ increased by increasing the rolling ratio. The intensity of the diffraction peak is related to the degree of order in the composite, including orientation and crystallization. Therefore, the XRD results indicated that the rolling process could not change the crystal type of the polymer, but it can significantly affect the PLA orientation.

In addition to the abovementioned diffraction peak, which was attributed to PLA, another diffraction peak with considerably lower intensity emerged at $2 \theta^{\circ} \approx 26.1^{\circ}$. This range corresponds to a d-spacing of $3.4 \AA$, which is the intershell spacing of carbon nanotubes, according to Quan's report [28]. For composites with the same MWCNT mass fraction, when the MWCNTs were randomly dispersed in the polymer matrix before the rolling process, a relatively low intensity distribution was expected. By increasing the rolling ratio, the diffraction intensity of the MWCNT peak increased, suggesting that the MWCNTs were preferentially oriented along the rolling direction. The orientation trend obtained from the XRD patterns was close to that of the oriented PLA.

To better understand the effect of the rolling process on the orientation, the orientations at different rolling ratios and various MWCNT mass fractions were calculated using the data in Figure 2 (applying Eq. [2]). These are also summarized in Table 2. The orientation was enhanced by increasing the rolling ratio by $1.5 \%-1.9 \%$, regardless of the MWCNT mass fraction. Moreover, at the same rolling ratio, increasing the MWCNT mass fraction enhanced the orientation. Thus, both the rolling ratio and MWCNT mass fraction clearly affected the molecular orientation; this was expected to improve the mechanical properties and eventually the electrical properties of the composites.

\subsection{Effects of rolling conditions on crystallization behaviors}

In addition to molecular orientation, the crystallization behaviors of the rolled composites, obtained under different rolling conditions, were investigated by performing
Table 2: Orientation of PLA/MWCNT composites at various rolling ratios.

\begin{tabular}{lrrr}
\hline $\begin{array}{l}\text { MWCNT mass } \\
\text { fraction (wt.\%) }\end{array}$ & $\begin{array}{r}\text { Rolling } \\
\text { ratio (\%) }\end{array}$ & $\begin{array}{r}\text { Half-width } \\
\left({ }^{\circ}\right)\end{array}$ & $\begin{array}{r}\text { Orientation } \\
(\%)\end{array}$ \\
\hline 3 & 0 & 10.84 & 93.98 \\
3 & 20 & 10.24 & 94.31 \\
3 & 40 & 8.74 & 95.14 \\
3 & 60 & 7.64 & 95.76 \\
3 & 80 & 7.59 & 95.78 \\
5 & 0 & 9.75 & 94.58 \\
5 & 20 & 9.17 & 94.91 \\
5 & 40 & 8.70 & 95.17 \\
5 & 60 & 7.26 & 95.97 \\
5 & 77 & 6.88 & 96.18 \\
10 & 0 & 8.72 & 95.16 \\
10 & 20 & 8.64 & 95.20 \\
10 & 40 & 7.72 & 95.71 \\
10 & 60 & 7.05 & 96.08 \\
10 & 80 & 5.86 & 96.74 \\
\hline
\end{tabular}

DSC analysis and measuring the crystallization, which affected their mechanical properties. In general, nanofillers, particularly CNTs, act as nucleating agents in composites [29]; crystalline layers may cover nanotubes [30], thus reducing or hindering the contact between CNTs. The crystallization and melting behaviors of the composites were studied (Figure 3). By using the data in Figure 3, the melting temperature $\left(\mathrm{T}_{\mathrm{m}}\right), \Delta \mathrm{H}_{\mathrm{m}}$, and $\Delta \mathrm{H}_{\mathrm{c}}$ were obtained, and $\chi_{c}$ was calculated by using Eq. 3 . The results are listed in Table 3.

As shown in Figure 3, all specimens exhibited three distinct peaks at the glass transition temperature $\left(\mathrm{T}_{\mathrm{g}} ; \sim 60^{\circ} \mathrm{C}\right)$, cold crystallization temperature $\left(\mathrm{T}_{\mathrm{c}} ; \sim 80^{\circ} \mathrm{C}-110^{\circ} \mathrm{C}\right)$, and $\mathrm{T}_{\mathrm{m}}$ $\left(\sim 170^{\circ} \mathrm{C}\right)$. In addition, the incorporation of MWCNTs led to the enhancement of the PLA crystallization, due to the nucleating effect of the filler, especially for high MWCNT mass fractions (i.e. $10 \mathrm{wt} . \%$ ). Owing to the large aspect ratio, high specific surface area, and strong interfacial interaction of the - $\mathrm{OH}$ and - $\mathrm{COOH}$ groups of the MWCNTs with the PLA matrix [31], the PLA molecules were easily bound to the surface of the MWCNTs, thus forming a sufficient number of nucleation centers and acting as crystal nuclei [32]. Moreover, $\mathrm{T}_{\mathrm{g}}$ of rolled PLA slightly increased with the increase in MWCNT mass fraction (Figure 3B). Hence, the incorporation of MWCNTs improved the PLA melting behavior.

Comparing Figures $3 \mathrm{~A}$ and $\mathrm{B}$ a correlation between the rolling ratio and crystallization behavior was found. Although the composite specimens exhibited the MWCNT nucleating effect, the crystal nuclei were destroyed during the rolling process, resulting in a 

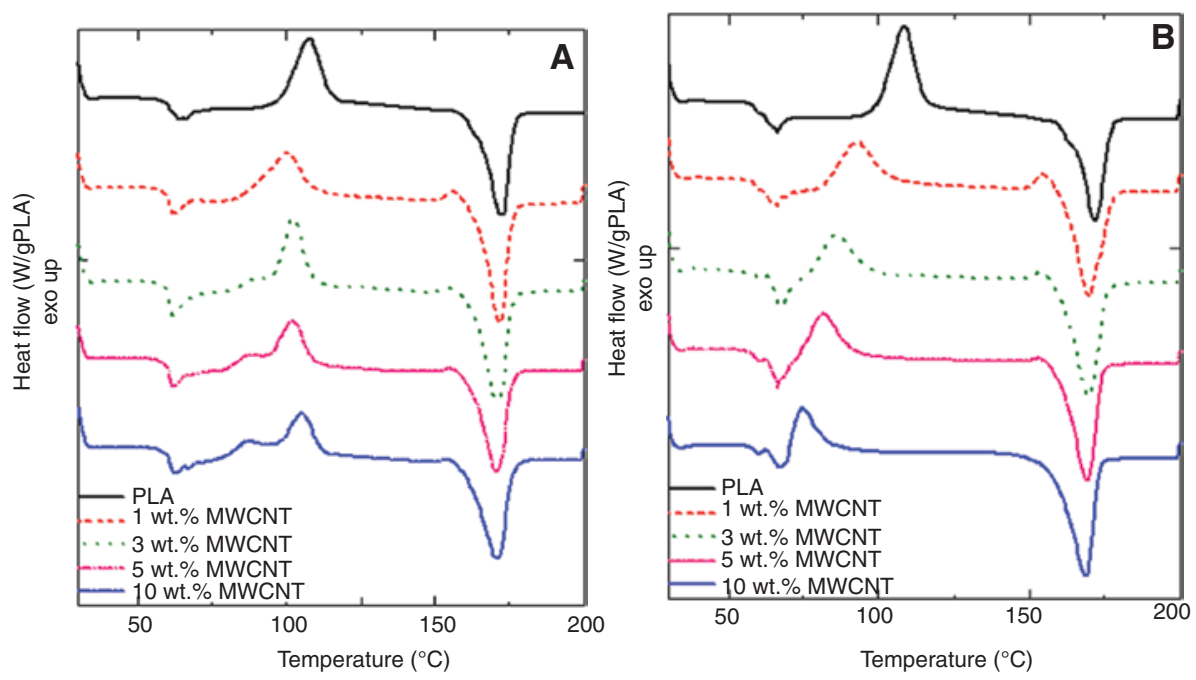

Figure 3: Differential scanning calorimetry curves of different PLA/MWCNT composites at rolling ratios of (A) $0 \%$ and (B) $75 \%$.

decrease in crystallinity. The same results are reported in Table 3. More interestingly, after the rolling process, the exothermic peak of the composite clearly shifted to lower temperature with the increase in MWCNT mass fraction (Figure 3B). This can be attributed to the fact that, during the rolling process, the original crystallization of PLA had been destroyed, and the nucleating effect of the MWCNTs attenuated, leading to a decrease in $\mathrm{T}_{\mathrm{c}}$ and PLA composite crystallization.

As shown in Table 3, for both unrolled and 75\% rolled specimens, $\mathrm{T}_{\mathrm{g}}$ and $\mathrm{T}_{\mathrm{m}}$ barely changed as the MWCNT mass fraction increased, whereas $T_{c}$ varied significantly. Regardless of the MWCNT mass fraction, $T_{c}$ of the unrolled composite was greater than that of the rolled specimen, particularly in the case of the $10 \mathrm{wt} . \%$ MWCNT composite. When the MWCNT mass fraction was $10 \mathrm{wt} . \%, \mathrm{~T}_{\mathrm{c}}$ decreased by $30^{\circ} \mathrm{C}$ after the rolling process. As for the unrolled composites, $\mathrm{T}_{\mathrm{c}}$ always exceeded $100^{\circ} \mathrm{C}$; however, for the rolled composites, $\mathrm{T}_{\mathrm{c}}$ dropped by $18.6 \%$, from 93.0 to $75.7^{\circ} \mathrm{C}$. Moreover, $\chi_{c}$ of the unrolled composites increased with increasing the MWCNT mass fraction. When the MWCNT mass fraction increased from 1 to $10 \mathrm{wt} . \%, \chi_{\mathrm{c}}$ increased by $53.8 \%$. The rolled composites behaved similarly to the unrolled composites. Thus, the MWCNTs played a critical role as nucleating agents for PLA, promoting its crystallization. Similar results have been reported by Barrau et al. [33].

To further verify the experimental results discussed above, the density method was utilized to measure the density of the composites, followed by the calculation of the crystallinity ratio. The density and crystallinity ratio of the composites as functions of the rolling ratio are shown in Figure 4. The densities clearly decreased with the rolling ratio, regardless of the MWCNT mass fraction. Likewise, for all specimens, $\chi_{c}$ exhibited trends similar to those of the density. The greatest effect of the rolling ratio

Table 3: Differential scanning calorimetry data measured on unrolled and $75 \%$ rolled PLA/MWCNT composite specimens.

\begin{tabular}{|c|c|c|c|c|c|c|c|}
\hline $\begin{array}{l}\text { MWCNT mass } \\
\text { fraction (wt.\%) }\end{array}$ & $\begin{array}{r}\text { Rolling } \\
\text { ratio (\%) }\end{array}$ & $\left.\mathrm{T}_{\mathrm{g}}{ }^{\circ} \mathrm{C}\right)$ & $\mathrm{T}_{\mathrm{c}}\left({ }^{\circ} \mathrm{C}\right)$ & $\mathrm{T}_{\mathrm{m}}\left({ }^{\circ} \mathrm{C}\right)$ & $\begin{array}{r}\Delta H_{m} \\
(\mathrm{~mJ} / \mathrm{mg})\end{array}$ & $\begin{array}{r}\Delta H_{c} \\
(\mathrm{~mJ} / \mathrm{mg})\end{array}$ & $\chi_{c}(\%)$ \\
\hline 0 & 0 & 59.7 & 107.8 & 173.2 & 34.0 & 29.6 & 4.7 \\
\hline 0 & 75 & 59.0 & 107.4 & 171.5 & 32.6 & 30.9 & 1.8 \\
\hline 1 & 0 & 59.3 & 100.8 & 172.0 & 35.2 & 27.7 & 8.1 \\
\hline 1 & 75 & 59.5 & 93.0 & 169.9 & 33.4 & 29.1 & 4.6 \\
\hline 3 & 0 & 59.1 & 102.7 & 171.4 & 34.9 & 27.0 & 8.7 \\
\hline 3 & 80 & 60.2 & 85.8 & 169.8 & 33.7 & 27.0 & 7.4 \\
\hline 5 & 0 & 59.1 & 102.3 & 170.9 & 33.0 & 23.1 & 11.1 \\
\hline 5 & 77 & 59.4 & 81.6 & 169.3 & 35.7 & 27.5 & 9.2 \\
\hline 10 & 0 & 58.8 & 105.6 & 170.8 & 32.3 & 21.8 & 12.5 \\
\hline 10 & 80 & 60.2 & 75.7 & 168.6 & 37.1 & 27.9 & 10.9 \\
\hline
\end{tabular}



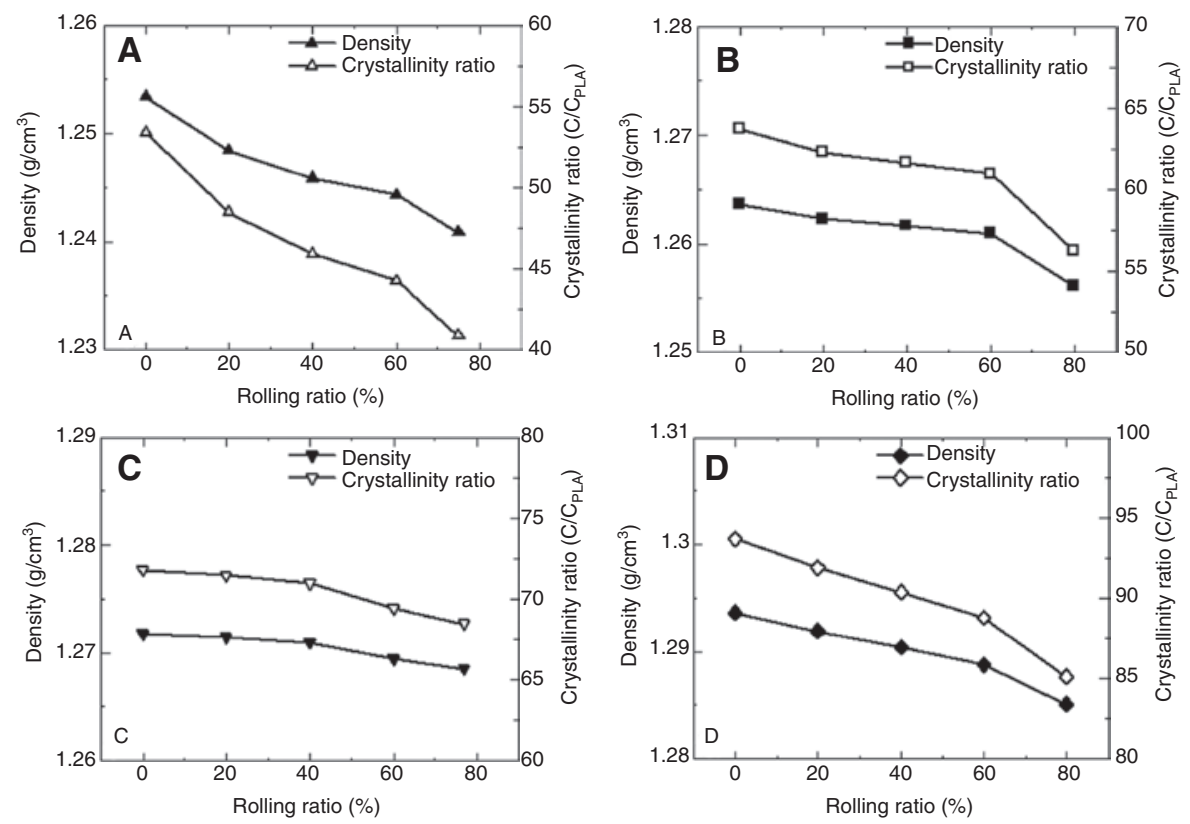

Figure 4: Effects of rolling ratio on the density and crystallinity ratio of (A) PLA/1 wt.\% MWCNT, (B) PLA/3 wt.\% MWCNT, (C) PLA/5 wt.\% MWCNT, and (D) PLA/10 wt.\% MWCNT composites.

emerged with the 1 wt.\% MWCNT composite (Figure 4A), which revealed that the original crystals were destroyed during the rolling process, with a significant decrease in crystallization. Similar results on other crystalline polymers, such as polyoxymethylene and polypropylene, have been reported by Pielichowski and Leszczynska [34] and Qiu et al. [35], respectively.

As shown in the four graphs in Figure 4, the density of the composites increased with the MWCNT mass fraction. Moreover, the crystallization of the composites was also enhanced by the increase in MWCNT mass fraction. These results are in agreement with the DSC results. Clearly, this behavior was due to the effects of the CNT nucleating agents.

\subsection{Effects of rolling ratio on mechanical properties}

The XRD and DSC results demonstrated that the orientation and crystallization of the composites were significantly affected by the rolling process. Pielichowski and Leszczynska [34] and Murata et al. [36] have reported that orientation and crystallization are associated with mechanical properties, such as tensile strength and fracture strain. Therefore, the tensile strength and fracture strain of the rolled composites were measured in two directions, i.e. parallel and perpendicular to the rolling direction. Figures 5 and 6 show the tensile strengths and fracture strains of the PLA/MWCNT composites at different
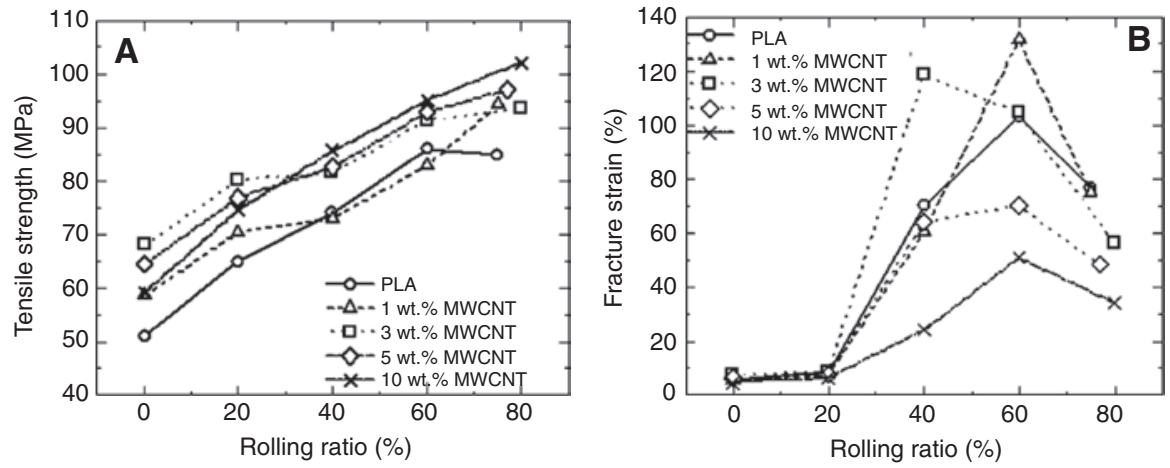

Figure 5: Tensile properties at various rolling ratios: (A) tensile strength and (B) fracture strain (parallel to rolling direction). 

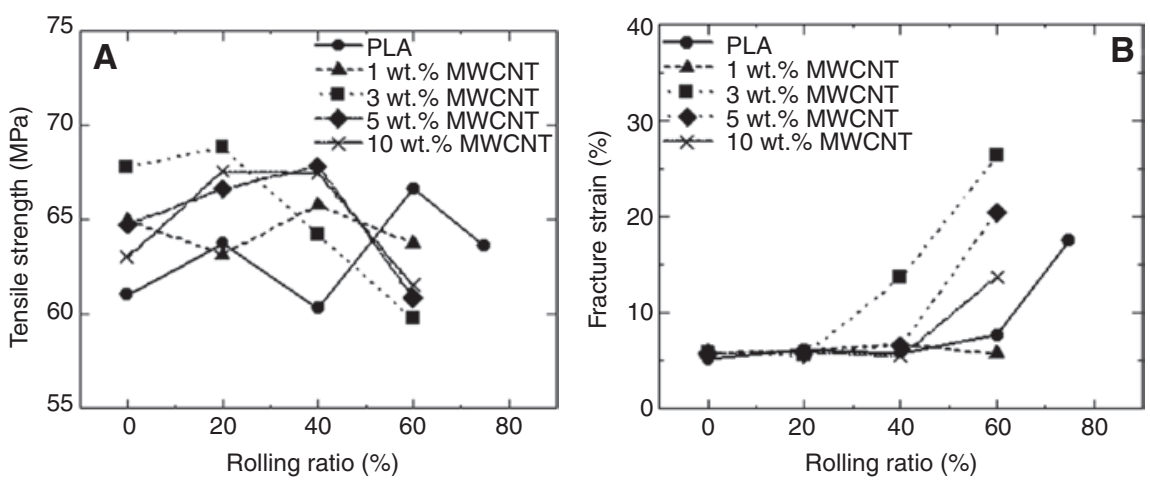

Figure 6: Tensile properties at various rolling ratios: (A) tensile strength and (B) fracture strain (perpendicular to rolling direction).

rolling ratios in the parallel and perpendicular directions, respectively.

As shown in Figure 5A, regardless of the MWCNT mass fraction, the tensile strength measured along the rolling direction increased almost linearly with the rolling ratio. For example, for the composite with $1 \mathrm{wt} . \%$ MWCNTs, when the rolling ratio increased from $0 \%$ to $75 \%$, the tensile strength increased by $60.9 \%$ from 58.6 to $94.3 \mathrm{MPa}$. However, the fracture strains showed erratic variations with the rolling ratio (Figure $5 \mathrm{~B}$ ); the maximum values appeared at rolling ratios of $40 \%$ and $60 \%$. Similarly, the fracture strain of the composite with $1 \mathrm{wt} . \%$ MWCNTs exhibited a sharp increase of up to $131.5 \%$ at the rolling ratio of $60 \%$, thus showing a $\sim 23$-fold enhancement, compared with pure PLA (i.e. the fracture strain of 5.3\%). Moreover, even when a large amount of MWCNTs (e.g. 10 wt.\%) were added, the fracture strain could still reach $50 \%$, demonstrating an increase of up to 10 times with respect to the unrolled specimen.

Meanwhile, the effects of the rolling ratio on tensile strength and fracture strain, measured in the perpendicular direction, were not so obvious (Figure 6). The tensile strength ranged from 60 to $70 \mathrm{MPa}$, and even if the fracture strain increased with the rolling ratio, its rise was not outstanding like that observed in the case of the parallel direction. Consequently, the results shown in Figures 5 and 6 suggested that the rolling process affected the mechanical properties in both measurement directions, parallel and perpendicular to the rolling direction; however, the effects in the different directions were quite distinct. Therefore, anisotropy occurred during the rolling process, resulting in obvious differences in the tensile properties of the rolled composites.

\subsection{Effects of rolling ratio on electrical resistivity}

The electrical resistivities of the composites were measured by using the standard specimens. In a previous work, the author found that surface and volume resistivities had similar trends [37]; thus, only volume resistivity was discussed in this paper. The effects of rolling ratio on volume resistivity measured along two different directions, i.e. parallel and perpendicular to the rolling direction, are shown in Figure 7A and B, respectively.
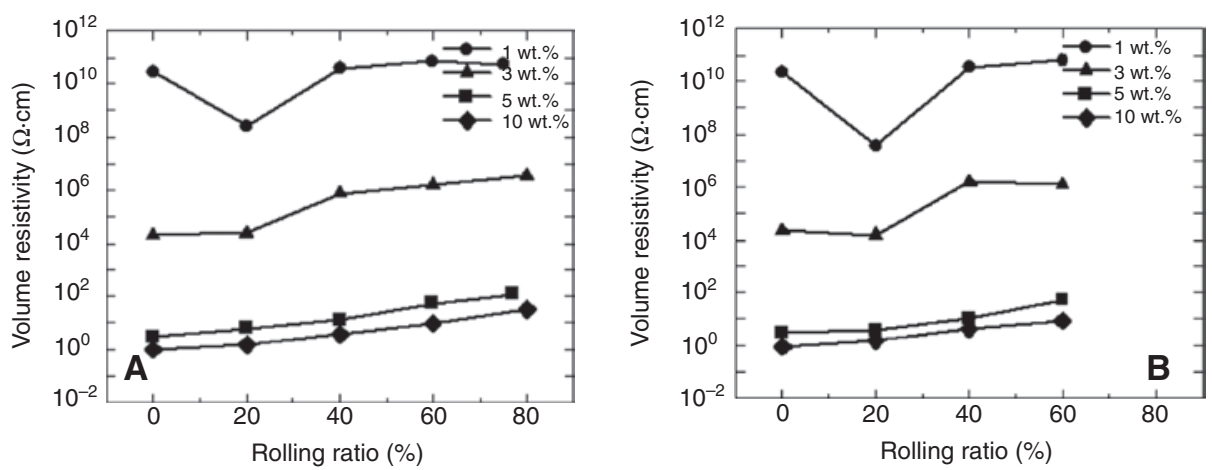

Figure 7: Volume resistivities of prepared composites at various rolling ratios: (A) parallel to rolling direction; (B) perpendicular to rolling direction. 
Clearly, regardless of the direction, the electrical resistivities increased slightly with the rolling ratio. Presumably, the MWCNTs were oriented during the rolling process. Remarkably, for the composites with $1 \mathrm{wt} . \%$ MWCNTs, the volume resistivity decreased by $2-3$ orders of magnitude (regardless of the parallel or perpendicular direction) at the rolling ratio of $20 \%$. This result was mainly due to the fact that the MWCNT mass fraction had not yet reached the percolation threshold, affecting by the process conditions. However, as the MWCNT mass fraction increased, the effects of rolling ratio on volume resistivity became small. Especially, when the MWCNT mass fraction increased to 5 or $10 \mathrm{wt} . \%$, the variation in volume resistivity was within one order of magnitude, $\sim 10^{0}-10^{1} \Omega \mathrm{cm}$. The results suggested that, when the MWCNT mass fraction did not reach the percolation threshold (i.e. within 3 wt.\%), the electrical resistivity was easily affected by the rolling process due to the randomly distributed MWCNTs. However, when the MWCNT mass fraction exceeded $3 \mathrm{wt} . \%$, dispersion and agglomerate sizes did not significantly affect the electrical resistivity, and thus the effect of the rolling ratio was not noticeable. However, for the mechanical properties, the differences in dispersion may be more critical, as the MWCNT agglomerates acted as imperfections and deteriorated the mechanical properties [38, 39].

Based on the above discussion on the electrical resistivity, the typical tensile fracture surfaces of the rolled composites were examined by SEM to observe the dispersion and orientation of the MWCNTs in PLA. Figure 8A and $\mathrm{B}$ show the representative microstructures of the 1 wt. $\%$ MWCNT composites obtained at rolling ratios of $0 \%$ and $60 \%$ in the rolling direction, respectively. Despite the small MWCNT mass fraction, a few MWCNTs could be found in PLA. Moreover, some clear differences between the two images could be observed. In Figure 8A, for the unrolled specimen (i.e. rolling ratio: $0 \%$ ), the MWCNTs randomly distributed in PLA, whereas conductive networks were not clearly observed, even in the presence of some agglomerations. Notably, as clearly shown in Figure 8B, the PLA/MWCNT composites were homogenized during the rolling process; however, the MWCNT dispersion and orientation did not change significantly. Consequently, the effects of the rolling process on the composite electrical properties were not prominent. Conversely, due to the orientation variation, the rolling process had a significant effect on the mechanical properties.
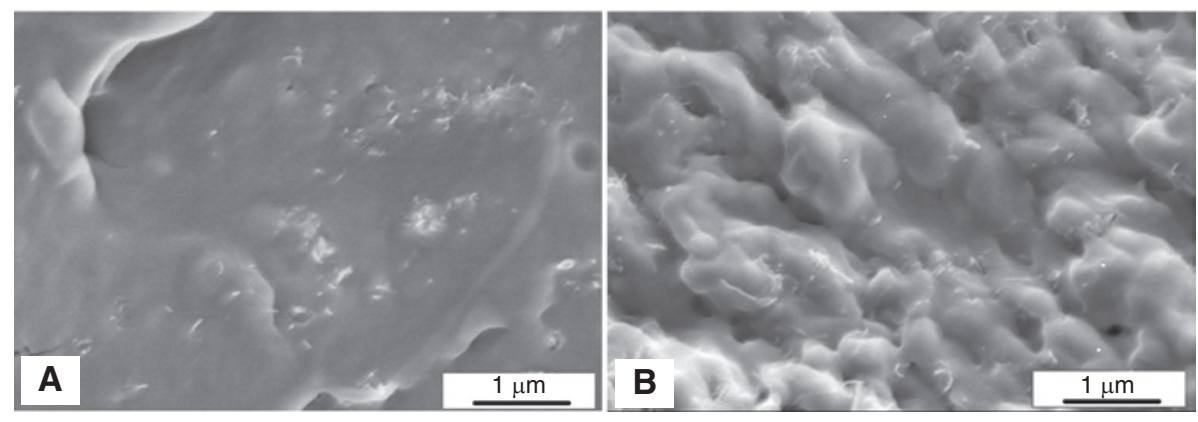

Figure 8: Scanning electron microscopy images of PLA/MWCNT composites with 1wt.\% MWCNTs: rolling ratios of (A) $0 \%$ and (B) $60 \%$ (parallel to rolling direction).
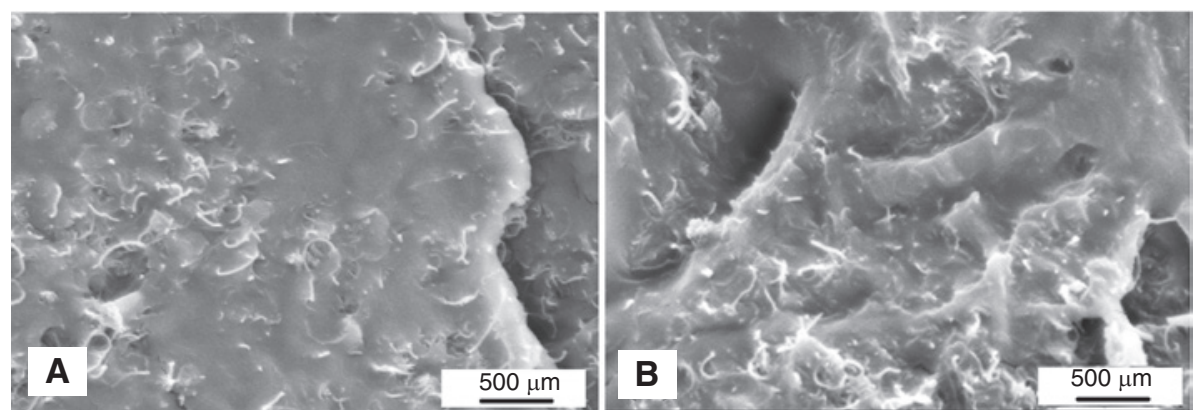

Figure 9: Scanning electron microscopy images of PLA/MWCNT composites with 5wt.\% MWCNTs: rolling ratios of (A) $0 \%$ and (B) $60 \%$ (parallel to rolling direction). 
Furthermore, SEM observations of the fractured surfaces of the $5 \mathrm{wt} . \%$ MWCNT composites were conducted to investigate the microstructures. The obtained results are shown in Figure 9. The MWCNTs dispersed in PLA in this specimen appeared more than those observed in the composite with 1 wt.\% MWCNTs (Figure 8). Moreover, no substantial differences between the two images were observed, indicating that the effect of the rolling process was not strong in the $5 \mathrm{wt} . \%$ MWCNT composites. In addition, the MWCNT dispersions and distributions were excellent in the unrolled and rolled composites, and the MWCNTs formed conductive networks in PLA, thus improving the electrical conductivity.

\section{Conclusions}

Five different PLA/MWCNT composites were produced with various MWCNT mass fractions. The crystal morphology, crystallinity, molecular orientation, mechanical properties, and electrical properties of the rolled composites were thoroughly investigated. Based on the obtained results, the most important factors affecting plastic processing of PLA/MWCNT composites for industrial applications are listed below.

1. The rolling process contributed to the molecular orientation. Moreover, the composite orientation slightly increased with the increase in MWCNT mass fraction.

2. On the one hand, the crystallinity of pure PLA dropped as the rolling ratio increased. On the other hand, the crystallinity was greatly increased by the incorporation of MWCNTs, which acted as nucleating agents in PLA. The density method also confirmed that, although the crystals were destroyed during the rolling process, the MWCNTs could improve the crystallinity of the composites. Furthermore, the surface plastic deformation occurred more easily than the interior deformation of the PLA. The deformation layer expanded with the rolling ratio.

3. When the rolling ratio reached $75 \%$, the tensile strength of the $1 \mathrm{wt} . \%$ MWCNT composite in the rolling direction increased from 58.6 to $94.3 \mathrm{MPa}$; and the fracture strain increased to $131.5 \%$ at the rolling ratio of $60 \%$. Moreover, due to the higher molecular orientation along the rolling direction, the tensile properties of the rolled composites in the rolling direction were mostly reinforced compared with those in the perpendicular direction.
4. The incorporation of MWCNTs improved the electrical conductivity of PLA. The electrical properties exponentially increased as the MWCNT mass fraction increased. When the MWCNT mass fraction was $5 \mathrm{wt} . \%$, the surface resistivity dropped to $10^{1} \Omega / \mathrm{sq}$. Finally, the effect of the rolling ratio on the electrical resistivity was not remarkable.

\section{References}

[1] Huang ZM, Zhang YZ, Kotaki M, Ramakrishnab S. Compos. Sci. Technol. 2003, 63, 2223-2253.

[2] Williams G, Trask R, Bond I. Compos. Part A-Appl. S. 2007, 38, 1525-1532.

[3] Nisawa M. Fundamentals of New Static Electricity Control Technology, Plastics Age: Japan, 25-65, 2009.

[4] Muller MT, Krause B, Kretzschmar B, Pötschke P. Compos. Sci. Technol. 2011, 71, 1535-1542.

[5] Villmow T, Potschke P, Pegel S, Haussler L, Kretzschmar B. Polymer 2008, 49, 3500-3509.

[6] Shah AA, Hasan F, Hameed A, Ahmed S. Biotechnol. Adv. 2008, 26, 246-265.

[7] Siracusa V, Rocculi P, Romani S, Rosa MD. Trends Food Sci. Tech. 2008, 19, 634-643.

[8] Eling B, Gogolewski S, Pennings AJ. Polymer 1982, 23, 1587-1593.

[9] Gogolewski S, Pennings AJ. J. Appl. Poly. Sci. 1983, 28, 1045-1061.

[10] Koronis G, Silva A, Fontul M. Compos. Part B-Eng. 2013, 44, 120-127.

[11] Oksmana K, Skrifvarsb M, Selinc JF. Compos. Sci. Technol. 2003, 63, 1317-1324.

[12] Ata S, Mizuno T, Nishizawa A, Subramaniam C, Futaba DN, Hata K. Sci. Rep. 2014, 4, 1-8.

[13] Wang L, Qiu J, Sakai E. J. Mater. Process. Tech. 2016, 232, 184-194.

[14] Miyata T, Masuko T. Polymer 1997, 38, 4003-4009.

[15] Puiggali J, Ikada Y, Tsuji H, Cartier L, Okihara T, Lotz B. Polymer 2000, 41, 8921-8930.

[16] Lim LT, Auras R, Rubino M. Prog. Polym. Sci. 2008, 33, 820-852.

[17] Nadella PH, Spruiell EJ, White LJ. J. Appl. Polym. Sci. 1978, 18, 3121-3133.

[18] Yu L, Liu H, Xie F, Chen L, Li X. Polym. Eng. Sci. 2008, 48, 634-641.

[19] Wang L, Qiu J, Sakai E, Wei X. Compos. Part A-Appl. S. 2016, 89, $18-25$.

[20] Kakudo M, Kasai N. X-ray Diffraction by Macromolecules, Kodansa Ltd.: Tokyo, 2005.

[21] Tham WL, Poh BT, M. Ishak ZA, Chow WS. J. Therm. Anal. Calorim. 2014, 118, 1639-1647.

[22] Kalb B, Pennings AJ. Polymer 1980, 21, 607-612.

[23] Tjong SC, Liang GD, Bao SP. Polym. Eng. Sci. 2008, 48, 177-183.

[24] Nampoothiri KM, Nair NR, John RP. Bioresource Technol. 2010, 101, 8493-8501. 
[25] Wei G, Ma PX. Biomaterials 2004, 25, 4749-4757.

[26] Marubayashi H, Asai S, Sumita M. Macromolecules 2012, 45, 1384-1397.

[27] Murata T, Qiu J, Wu X. Polym. Eng. Sci. 2013, 53, 2573-2581.

[28] Quan H, Zhang S, Qiao J, Zhang L. Polymer 2012, 53, 4547-4552.

[29] Bhattacharyya AR, Sreekumar TV, Liu T, Kumar S, Ericson LM, Hauge RH, Smalley RE. Polymer 2003, 44, 2373-2377.

[30] Ryan KP, Cadek M, Nicolosi V, Blond D, Ruether M, Armstrong G, Swan H, Fonseca A, Nagy JB, Maser WK, Blau WJ, Coleman JN. Compos. Sci. Technol. 2007, 67, 1640-1649.

[31] Yoon JT, Jeong YG, Lee SC. Polym. Adv. Technol. 2009, 20, 631-638.

[32] Li Z, Zhao X, Ye L, Coates P, Caton-Rose F, Martyn M. J. Biomater. Appl. 2014, 28, 978-989.
[33] Barrau S, Vanmansart C, Moreau M, Addad A, Stoclet G, Lefebvre JM, Seguela R. Macromolecules 2011, 44, 6496-6502.

[34] Pielichowski K, Leszczynska A. J. Polym. Eng. 2005, 25, 359-373.

[35] Qiu J, Kawagoe M, Mizuno W, Morita M. Trans. Jpn. Soc. Mech. Eng. A. 2000, 66, 867-874.

[36] Murata T, Qiu J, Sakai E, Wu X, Kudo M. Adv. Mater. Res. 2012, 391-392, 595-599.

[37] Wang L, Qiu J, Sakai E, Wei X. Sci. Eng. Compos. Mat. 2017, 24 , 163-176.

[38] Wang L, Qiu J, Sakai E. Polym. Composite. 2015, DOI: 10.1002/ pc.23801.

[39] Qiu J, Wang L, Uchiya K, Sakai E. Polym. Composite. 2016, 37, 3245-3255. 